\title{
Searching for Evidence of Alternative Preferences, Public as Opposed to Private
}

\author{
by \\ Clifford S. Russell, Thomas Bue Bjørner, and Christopher D. Clark

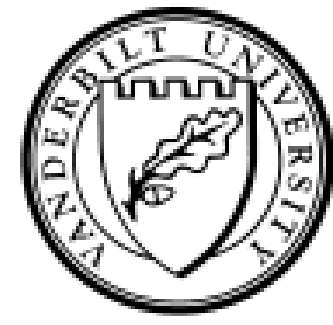

Working Paper No. 01-W01

January 2001

DEPARTMENT OF ECONOMICS

VANDERBILT UNIVERSITY

NASHVILLE, TN 37235

www.vanderbilt.edu/econ 
$\mathrm{M}: \backslash$ oldpc $\backslash \mathrm{Cliff} \backslash$ version5.wpd

Version 5

\title{
Searching for Evidence of Alternative Preferences, Public as Opposed to Private ${ }^{1}$
}

\author{
January, 2001 \\ Clifford S. Russell ${ }^{2}$, Vanderbilt University, U.S. \\ Thomas Bue Bjørner ${ }^{3}$, AKF, Denmark \\ Christopher D. Clark, University of South Alabama, U.S.
}

1 The authors are grateful for support of this research by our funders: In the U.S., the National Science Foundation, grant\# 9727376; in Denmark, the Danish Environmental Research Program. Earliercommentators who have helped us with insights and suggestions, but of course have no responsibility forremaining inadequacies include: Alex Dubgaard, Richard Ready, and Olaf Johanss on-Sten man. Finally, we wish to thank Laura Mørch Andersen, Camilla Damgaard, and Molly Hadley Jensen for invaluable research assistance.

2 Corresponding author in general: Vanderbilt Institute for Public Studies, $120718^{\text {th }}$ Avenue South, Nashville, Tennessee 37212. E-mail: cliff.russell@vanderbilt.edu.

3 Corresponding author with respect to the Danish part of the study: AKF (Institute of Local Government Studies - Denmark), Nyropsgade 37,DK-1602 Copenhagen V, Denmark. E-mail: tbb@akf.dk 


\begin{abstract}
Important economic thinkers such as Sen, Arrow and Harsanyi have argued for the existence of multiple preference orderings, allowing individuals to make choices, both when only private welfare is at stake and when the good of some collective is involved. Further, recent literature has shown that the presence of altruistic, as opposed to "private", preferences may have important implications for environmental regulation and the optimal provision of public goods. However, only limited empirical work has been carried out to test for the presence of such preferences. This paper presents an empirical study, done in Denmark and the US, that supports the existence of such preferences. More precisely, the study finds that in both countries expressions of two types of altruistic preferences can be triggered in a predictable, controllable way by small framing changes in a questionnaire. It is suggested that the method used may itself be useful in further studies testing for other varieties of altruism.
\end{abstract}

JEL Classifications: A13, B40, D64, H41, Q26, Z13

Key-words: Altruism, committed and sympathetic preferences; framing 


\section{Introduction}

\subsection{Background}

Arguments for the existence of "public" preferences as part of sets of multiple orderings possessed by individuals have received the attention of some of the $20^{\text {th }}$ century's most prominent economists. Examples of this long line of consideration include Harsanyi, 1955; Arrow 1963; Sen 1977; Kolm, 1983 and 1994; and Beckerman and Pasek, 1997. But it goes back at least to Pareto, as discussed by Kolm (1983). Much of the argument in these and similar papers and lectures might be labeled $a$ priori - - people must have multiple ways of looking at the world and be able to separate, for example, judgments about what is in their own interests from judgments about what should be done in society. In this sense, the work can be seen as criticizing and extending the foundations of traditional utility theory. ${ }^{1}$

If simple criticism of the traditional theory is not to be the stopping point, however, it is necessary to specify a utility function that allows the rational maximizing person to function in a world of choices and limited resources, while no longer being totally selfish. A little thought is likely to suggest that there will be more than one possibility for modeling what might broadly be called “altruism.” Here, for example, are three possibilities supplied by Johansson (1997) that include concern for some measure of the welfare of others and thus extend the simple, selfish notion of utility, which here can be written for individual $i$ as:

$$
\mathrm{u}_{\mathrm{i}}=\mathrm{u}\left(\mathrm{x}_{\mathrm{i}}, \mathrm{z}_{\mathrm{i}}, \mathrm{Z}\right)
$$

1 This is most explic it in the work of Sen, of which the 1977 paper is a particular good example. 
where $\mathrm{x}_{\mathrm{i}}$ is consumption of a "clean good" (one without negative externalities); $\mathrm{z}_{\mathrm{i}}$ is consumption of a "dirty" good (one that creates negative externalities); and $\mathrm{Z}$ is the aggregate negative externality created by $\sum_{i}$, the aggregate consumption of all consumers of $\mathrm{z}$.

One alternative, called "pure altruism," adds the welfare of all others to the arguments of u. Thus: $\mathrm{u}_{\mathrm{i}}=\mathrm{u}\left(\mathrm{x}_{\mathrm{i}}, \mathrm{z}_{\mathrm{i}}, \mathrm{Z}, \mathrm{U}\right)$, where $\mathrm{U}=\sum_{j \neq i} \mathrm{j}$. "Paternalistic altruism" brings into the individual's utility function the negative externality experienced by others, $Z_{p}$, but not the utility level or levels produced for others: $\mathrm{u}_{\mathrm{i}}=\mathrm{u}\left(\mathrm{x}_{\mathrm{i}}, \mathrm{z}_{\mathrm{i}}, \mathrm{Z}, \mathrm{Z}_{\mathrm{p}}\right) .^{2}$

"Genuine altruism", on the other hand, is captured in a rather different way, since in this formulation individuals care for others without themselves deriving utility directly from the utility of others. Thus, the genuine altruist might be said to maximize $\omega=u_{i}+\theta(U) \cdot{ }^{3} \omega$ therefore might be seen as a "meta-utility function," and the subtle change from "pure" altruism that it incorporates turns out to make a difference, as discussed briefly below.

More recently, attention has turned to the welfare implications of altruistic behavior in relation to contingent valuation and cost-benefit analysis (e.g. Milgrom, 1993; McConnell, 1997; and Johansson-Stenman, 1998 and 1999), or optimal externality-correction taxes (Johansson, 1997). Not surprisingly, it appears that altruism has different implications depending on the way that it is

2 Sticklers for realism have pointed out that the very notion "pure" altruism assumes that one individual can know the utility effects of actions or goods on the utility levels of others...indeed of multiple others. This runs counter of course, to most of modern welfare econ omics. (eg: McConnell, 1997.)

3 In Johanss on-Sten man, 1999, the formulation is given as: $\Omega_{\mathrm{i}}=\omega_{\mathrm{i}}\left(\mathrm{u}_{\mathrm{i}}, \mathrm{u}_{1}, \ldots, \mathrm{u}_{\mathrm{N}}\right)$ written in the notation used above. In that paper J-S also distinguishes a paternalistic version of genuine altruism in which the environ mental situation of each other person en ters instead of the utility level. 
modeled. Thus, in the case of pure altruism one gets the same result with respect to optimal taxation and in cost benefit calculations as if there were no altruistic behavior. Optimal public policy will, however, be affected by other forms of altruism. Johansson finds, for example, that the optimal tax, subject to his specification of genuine altruistic preferences, is lower (compared with the standard Pigovian tax), while the optimal tax is higher when altruism is paternalistic. He notes that the latter result may appear counterintuitive, since, because of the paternalistic altruism, the consumers have already to some extent reduced their consumption of the externality-causing good. The explanation is that the social optimum has changed too, also as a result of the altruism.

Complicating matters is the thread of the psychological literature, also with venerable roots (eg:Lapiere, 1934), that asserts the lack of any well-defined preferences over unfamiliar choices or to be applied in unfamiliar, hypothetical situations ( Fischhoff, 1991). This thread is twined with a more recent one that stresses the construction of preferences in the act of considering new choices or new situations. (For example, Gregory, et al., 1993; Slovic, 1995). Taken together, these threads imply that no prior preferences can be assumed when what is at stake is some feature of public policy about the environment. But, further, testing that proposition is probably very difficult (perhaps even impossible) because the very process of trying to probe for such preferences would spur their creation. And how the questions are asked would be a very sensitive matter, because we would not want to cue the respondent on the identity of the socially "correct" answer. 


\subsection{This study in brief}

The purpose of the study reported here, then, is to look for empirical evidence of the existence of multiple preference orderings, and to do so in a way that arguably minimizes the applicability of the preference-construction argument as an explanation of the results. Further, the study method was applied in two countries, Denmark and the United States, with the goal of investigating whether what we might call informal hypotheses about relevant national "characters" are supported by the evidence.

The approach used involved an elaboration (as described in Section 2) of the following idea. Three independent subsamples of individuals are asked about their preferences (most and leastpreferred levels) for provision of a "good" with the "public" characteristic that once "provided" it is provided to all consumers of the services of a particular public park. (The good is the set of management policies arrayed on a scale from least to most intensive.) Just before the preference questions are asked, the respondents are exposed to a brief "framing" paragraph that purports to explain why the questions are of interest. Each of the subsamples receives a different "frame." One of these stresses the individual's interests; a second describes the importance of the park (and so, implicitly, its policies) for "others" from the surrounding urban area; the third notes the importance of the park as the remnant of a nearly vanished (locally, at least) type of eco-sys tem. The first frame is designed to trigger "private" preferences, the second to call out Sen's (1977) "sympathetic" preferences (in our context these reflect Johansson's (1997) paternalistic altruism); and the third is aimed at Sen's (1977) "committed" preferences (Johansson-Stenman identifies this with the 
paternalistic version of genuine altruism) - - in this case the commitment being to the idea of ecological system preservation. The hypotheses to be tested are those about how the choices of least and most preferred management intensity levels will differ according to the frame to which the respondent has been exposed.

\subsection{Previous Empirical Work}

Despite the fundamental difficulties noted above, there have been some efforts to empirically investigate the existence of altruistic preferences. One example is Hudson and Jones (1995), who found support for altruism in an hypothetical voting framework. They presented respondents with alternative policies and then asked them which policy they favored, which policy they thought would be in their self-interest, and, finally, which policy they considered to be in the public interest. Hudson and Jones found the (self-identified) public interest answer about twice as highly correlated with the favored policy as the self-interest answer. They also found that this correlation increased with education and income.

On the other hand, in a study of the motivation of farmers' actions to limit negative environmental impacts of their activities, Weaver (1996) found that expected effects on private profits were the most important motivation for the pro-environmental actions undertaken. However, he also noted that altruistic motivation was an additional determinant of environmental effort carried

out by the farmer. The motivation of the farmers was explored by direct questions (e.g. "Did you do X because....").

Ajzen et al. (1996) investigated the possibility of manipulating "motivational orientation" 
in the context of a contingent valuation survey setting. The manipulation consisted of confronting the sample (192 total respondents) with a series of 45 strings of words that could be made into sentences by correct rearrangement and removal of an irrelevant word. Half the sample faced (potential) sentences expressing an altruistic orientation, while the other half worked with expressions of individualistic sentiments. After this exercise, all the respondents were asked to state their willingness to pay (WTP) for a series of goods reflecting different combinations of public and private characteristics. The researchers found that stated WTP for the pure public good was significantly larger for the altruistically "oriented" respondents than for those exposed to the individualistic statements. ${ }^{4}$ For the semi-public and private goods no significant difference in the WTP could be found. Compared to the study presented here, Ajzen et al. went to greater lengths to motivate respondents (“trigger" alternative preference expression).

It should also be noted that various other empirical observations have been interpreted as related to altruism. For example, it has been suggested that experimental evidence of (what is labeled as) fairness could be an expression of altruism. ${ }^{5}$ Another example comes from the valuation literature, where it has been proposed that the discrepancy between dichotomous choice and openended WTP responses in hypothetical survey contexts occurs because the good at issue in these

4 The public good was students' do nation (as part of their tuition fee) to a campus movie theatre. What here is labelled "pure public good" corresponds to provision of the good after the students were likely to have graduated . The original label used by Ajzen et al. was "public good with low personal relev ance."

5 See Andreoni (1995) for discussion of experimental evidence regarding public good provision and econom ic theory. However, as Andreoni notes, the way in which many of these experiments are set up makes it difficult to determine whether these deviations are the result of kindness or simply to confusion on the part of the participants. See Forsythe etal. (1994), Fehr et al. (1993), Prasniker and Roth (1992) and Andreoni (1988) for other discussions of cooperation and fairness in bargaining and game experiments. 
studies acts as a symbol for strongly felt moral concerns see e.g. Brown et al. (1996). A general critique of valuation studies along these same lines is given by Sagoff (1988).

Finally, what might be called the "curse" of hypotheticality must be addressed. That is, if respondents to survey questions or subjects in laboratory experiment settings do not believe that real and reasonably serious consequences to them will follow from their answers/responses they may feel free to express any sentiment or exhibit any behavior. This argument against the reliability of contingent valuation results (e.g.: Bohm, 1994 ) and as an explanation of laboratory "preference reversals" (Bohm, 1994 $)$ also can be applied to all the above work and to the technique used here, as described below. Logically, there can be no completely convincing defense against it. But we believe it is possible to offer in "mitigation" the observation that real, local public goods, the provision of which might be affected by local sentiments, suitably expressed to decision makers, arguably offer less scope for unthinking or playful responses. Ajzen's use of a campus movie theater in the context of student subjects is a case in point. Our approach uses non-student respondent samples, but the key questions are asked about the management strategies for reasonably familiar local forested parks.

\subsection{The Plan of the Paper}

The rest of the paper is organized as follows: Section 2 contains a fuller description of the study method, including the frames and the managementpolicies as well as information about the samples (sizes, characteristics, and response rates). The third section reports the empirical results. The last section offers conclusions and thoughts about further research. 
Briefly to anticipate the results: We find that the frame designed to trigger committed preferences (hereafter the committed frame) has a statistically significant effect in the predicted direction. The frame designed to trigger sympathetic preferences (the "public frame") for many individuals also triggers the hypothesized effect on expressed preferences. In this case the results are not so strong statistically, though interestingly, they are stronger in the US than in Denmark.

\section{Description of Research Method}

In this section, the survey instrument at the heart of the method is first described in general terms. Then the frames and management intensity preference questions are covered in more detail. Our hypotheses about the response patterns expected from the different frames are set out, and the section concludes with information about data collection.

\subsection{The Instrument Overall}

Similarly designed surveys were sent to respondents in the U.S. and Denmark. Both asked questions about the preferences for the management of a medium-sized forest area, with a lake. The settings were Radnor Lake Natural Area (RLNA) within Nashville, Tennessee, and Tokkekøb Hegn (TH), in suburban Copenhagen.

The outline of the questionnaires was as follows: (1) a short description of the respective focus areas; (2) questions about the respondent's outdoor activities (both in general and in the focus area); 
(3) a request for the respondent to indicate his/her most and least preferred levels for intensity of recreation management for the forest and the lake. The three different frames constituted the introduction to these questions about preferred intensity levels; (4) WTP questions; ${ }^{6}(5)$ a request for the respondent to indicate whether s/he, when responding to the questions about preferred intensity levels, was considering only her/himself (including close family), other potential users, the flora and fauna in the area, or future generations; and (6) standard socioeconomic background questions. ${ }^{7}$ The debriefing question about what or who the respondent was considering when he/she answered the intensity level questions was included to elicit some evidence about what respondents thought (or at least wanted to claim) they were doing. The U.S. version of this question asked which one of the four motivations was most important in influencing the answers given. The Danish version asked for a rating of the importance of the same motivations.

\subsection{Frames and questions about preferences}

The three "frames" (in their English version) are gathered in Table 1. Some keywords for the respective frames have been put in italics to ease comparison.

6 Nothing more will be said here about the WTP question responses becau se they are not directly relevant to our primary concern. For more information on this aspect of the study see Bjørner, et al. 1998. The important thing to note here is that the WTP question came after the management intensity questions.

7 In Denmark most of the socioecono mic background variables were draw $\mathrm{n}$ from official registers an d were also available for non-respondents. In the U.S., census tract average s were av ailable for non-responden ts and respondents, and for the latter supplemented the self-reported information. 


\section{Table 1. Frames designed to trigger the following preferences}

\begin{tabular}{|l|l|}
\hline Private & $\begin{array}{l}\text { Consider the land and wa ter activity le vels below. Base d on what you per sonally } \\
\text { prefer, please select one level as best and one level as worst. Radnor may be used } \\
\text { as an example as you consider the levels. You might visit a park like Radnor to } \\
\text { exercise; to see birds, animals, or wildflowers; or to attend educational programs. }\end{array}$ \\
\hline Public & $\begin{array}{l}\text { Radnor Lake may be used as an example as you consider the land and water } \\
\text { activities below. Parks like Radnor, located close to where lots of people live are } \\
\text { important for many people for different reasons. Some people visit to exercise, } \\
\text { others to see birds or wildflowers, and still others to attend educational programs. } \\
\text { Based on what you think should be available for visitors, please select one of the } \\
\text { levels listed as best and one as w orst. }\end{array}$ \\
\hline Committed & $\begin{array}{l}\text { Radnor Lake may be used as an example as you consider the land and water } \\
\text { activity levels below. The Radnor area is } \text { unusual because it preserves a small part } \\
\text { of the hilly Tennessee forest within Metropolitan Nashville. Most of the rest of this } \\
\text { forest is rapidly being developed for suburban housing. The lake at Radnor was } \\
\text { formed by a dam made by hum ans, but now plays its own natural role as home to } \\
\text { wild fowl, fish, snakes, turtles, insects and other species. Please select one level as } \\
\text { best and one as worst. }\end{array}$ \\
\hline preservation
\end{tabular}

Note: These are the versions from the US survey. The obvious changes a re made to translate to the Danish site, but we attempted to keep the "message" the same.

After being presented with one of these three frames, the respondent was asked to indicate his/her most- and least-preferred management intensity levels for land and water activities separately on scales running from 1 to 5. Level one involved a very low intensity of use and facility development, while level 5 involved many more allowed activities that in turn implied more noise and evidence of human use generally. The text used to describe each intensity level is presented in Appendix 1. These descriptions were supported by two color photographs for each level. (Some of these were computer-manipulated in order to more precisely illustrate the text description of the respective 
level.) Together, the frames and the description of the indices (in text and photographs) made up the description of the "good" being asked about. Note that the framing text only accounted for a small part of the total space used to describe the good. (Measured vertically, it constituted less than $10 \%$ of the total space dedicated to the description of the good.) We tried in this way to reduce the risk that any effects from the frames could be claimed to be an artifact of our forcing the construction of particular preferences. ${ }^{8}$

\subsection{A priori hypotheses ${ }^{9}$}

We expected the first frame to produce expressions of private preferences and take the results for this sample as the benchmarks, while the second and third frames were expected to trigger expressions of public and committed preferences, respectively. We hypothesized that if these are expressed they will be seen as differences in the mean levels and ordering of most and least preferred intensity levels from the benchmark. For the benchmark case we expect that the typical pattern will be that the most preferred intensity level is lower than the least preferred level (e.g. the most preferred intensity level could be 3 , while the least preferred could be 5). ${ }^{10}$ If the public frame successfully triggered sympathetic preferences, we expect to see these revealed as a reversal of the "shape" of the relative

8 Copies of the original survey instruments are available from the respective corresponding authors.

9 Our a priori hypotheses have also been described in Bjørner et al. (1998), which was presented before the first questionnaires were sent out in Nashville. Thus, by "a priori hypotheses," we actually do mean hypotheses that were formed before any data were collected.

10 This a priori hypothesis derived from a preceding study (Russell et al., 2001), where one of several different forest attributes was a land-based activity index structured similarly to the one used here. 
preferences over management intensity compared to the private pattern. Thatis, we hypothesize that the public frame will produce a significant tendency for respondents to state a most-preferred level above their least-preferred level. So we expect to see higher most preferred and lower least preferred levels compared to the benchmark. ${ }^{11}$

If the third frame were successful in triggering committed preferences, we would expect those to appear as what might be called an accentuation of the benchmark private pattern. That is, most preferred intensity levels should be lower on average compared with the benchmark (i.e.: the most preferred intensity level could be 1 or 2), while we expect that there would be a higher probability that the least preferred intensity level will be high.

We also expect to find that respondents who are not very familiar with the good in question will be more sensitive to framing effects. For people who rarely or never visit the area, the management options would tend to have more clearly the character of a public good than they do for people who often visitit. (This hypothesis is consistent with the findings of Ajzen et al. (1996).)

We also expect that expressions of both sympathetic and committed preferences will be stronger in Denmark than in the US, though in this regard our test can only be interpreted with caution, because the survey instruments in the two countries will inevitably be slightly different. In particular, it is essentially impossible to guarantee that the "triggers" are linguistically strictly

11 This original hypothesis in effect assumed that respond ents who are acting sympathetically will assume that not every one has the same tastes they do and will accom moda te those differing tastes by allowing for a greater range of allowable activities in the park. As we note below after examining the results, if "sympathy" here takes the form of paternalistic altruism, the effect on choice will be that others should be given what the respondent thinks is good for them. 
equivalent because of subtle differences in cultures and word connotations.

The emphasis in the study is on the analysis of respondent preferences for intensity of use of

the forest and lake, as expressed by responses to the most- and least-preferred management intensity questions because, as suggested by the research of others, the WTP questions could, in themselves, be a trigger for individualistic or private preferences (Stern and Dietz, 1994). However, we do not expect the statements about most- and least-preferred intensity levels to be contaminated by the WTP formulations, as the latter appear later in the questionnaire.

\subsection{Data collection and response rate}

Respondents were selected from ZIP codes close to the Radnor Lake and Tokkekøb Hegn natural areas in order to obtain responses from actual and potential users of these areas. In the US, surveys were sent to 4500 respondents -1500 for each frame. In Denmark, surveys were sent to 3000 respondents - 1000 for each frame. The US surveys were mailed in September, 1998, and the Danish surveys in April, 1999. In both cases a postcard reminder was sent after two weeks and a second reminder (including a new questionnaire) a couple of weeks later to non-responders. Response rates 
of $54 \%$ and $70 \%$ were obtained in the US and Denmark, respectively. ${ }^{12}$ Our a priori expectation for a higher response rate in Danmark was the reason for the differences in the sample sizes.

\section{Empirical results}

The empirical analysis is divided into four parts. First, we examine the effect of the frames (and socioeconomic characteristics) on preferred intensity levels. Second, we ask whether framing and familiarity with the park interact. Third, we explore the respondents' stated motivation when answering the preferred intensity level questions.

\subsection{Effects of frames on preferred intensity levels}

The most- and least-preferred forest management intensity levels across the frames in the US and Denmark are illustrated in Figures 1 through 4. Figure 1 shows the distribution of the responses to the most preferred question for the forest area at RLNA by frame. The vertical axis measures the share $(\%)$ of the various choices. The middle bar in each case represents the responses to the

12 There were no significant differences in the response rates between the different frames in Denmark (but note that the frames were not located at a place in the questionnaire where one would expect large differences in responses due to the framing). In the US, a higher percentage of questionnaires with the committed frame were completed and returned than either of the other two versions. However, this difference seems to be more a function of the geographic distribution of the surveys. (Unfortunately, respond ents residing in zip codes near Radnor Lake received a higher proportion of the version with the committed frame than did respondents in more distant zip codes). After controlling for the effect of distance and various neighbourhood characteristics on response rate, the frames did not have a significant effect on the likelihood of a respondent completing and returning the survey in regressions analysing these responses. However, the above "mailing house c urse" did result in the sub-samples in the U.S. study being different from each other in socio-economic dimensions such as age, income, and education. 
benchmark private frame, while the left bar Figure 1. Most Preferred Forest Levels (US). refers to the public frame and the right bar to

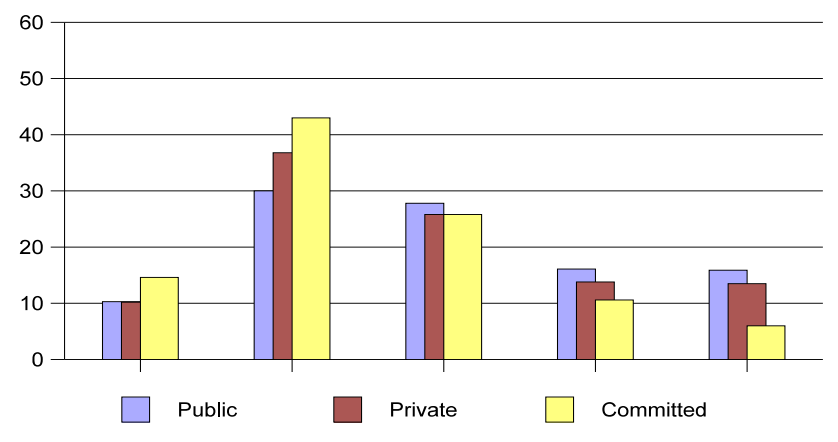
intensity levels at $\mathrm{TH}$ in Denmark, while Figures 3 and 4 show distributions of the least Figure 2. Most Preferred Forest Levels (DK). preferred forest management levels in the US and Denmark, respectively.

Ignoring for a moment the differences according to frame it appears that intensity

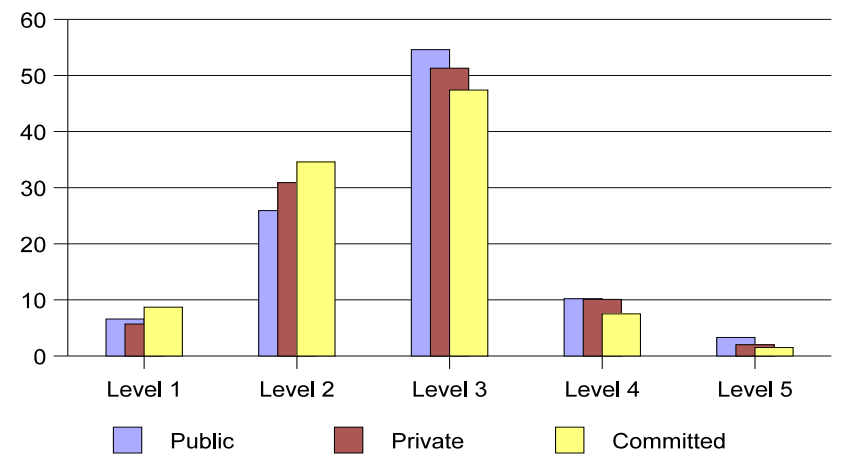
level 2 is generally the most preferred forest level in US, with level 3 as runner up. In Denmark it is the other way around. The lowest and highest intensity levels (1 and 5) are the levels least often chosen as the most preferred levels in both countries. Not surprisingly, Figure 3. Least Preferred Forest Levels (US).

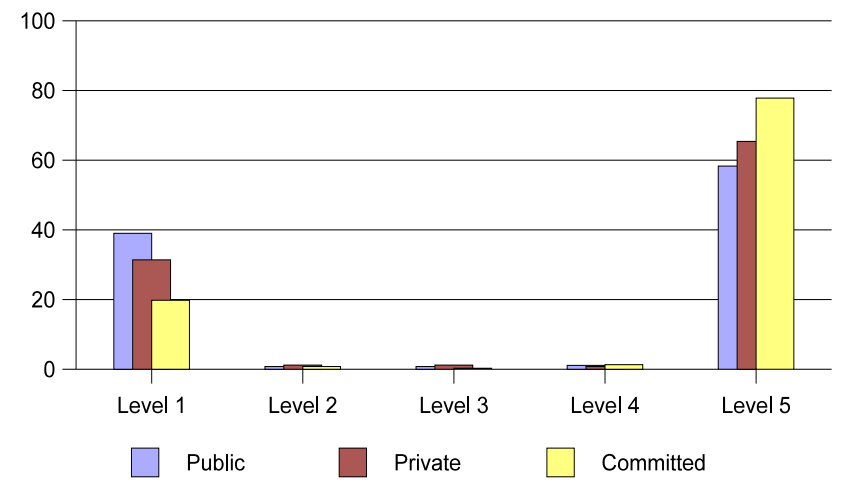

Figure 4. Least Preferred Forest Levels (DK).

Figures 3 and 4 indicate that respondents in both countries almost always choose one of the two end-points of the intensity index as their least preferred intensity levels, with the highest

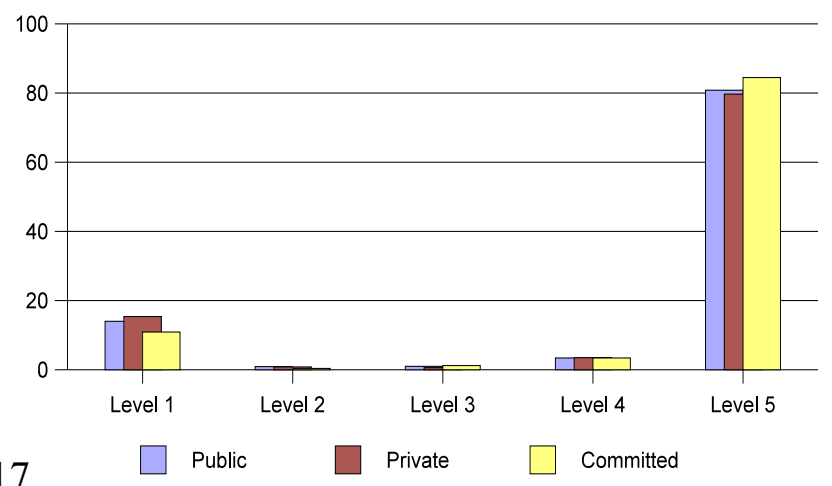


intensity level easily being the most popular choice as the least preferred intensity level. ${ }^{13}$ These general observations apply to all three frames. That is, even though responses do seem to vary according to frame, the changes are not dramatic enough to alter these patterns. Similar patterns and comments applied to the responses to the questions dealing with management choices for the water bodies at the two parks.

Focusing, now, on the differences between the frames it appears that by and large these seem to correspond well with our hypotheses. Respondents rec eiving the public frame seem more likely to prefer higher intensity levels (Levels 3 through 5) than those receiving the private frame, in both the US and Denmark. Similarly, respondents in both countries who received the committed frame were more likely to choose the lowest intensity levels (Levels 1 and 2) as their most-preferred. In the US, $78 \%$ of the respondents receiving the committed frame, but only $58 \%$ of the respondents receiving the public, chose the highest intensity level as their least-preferred. In Denmark, $85 \%$ of the respondents receiving the committed frame chose the highest level as the least preferred, while $80 \%$ of those receiving the public frame made the same choice.

As a first approximation, the means of the most- and least-preferred levels can be used to summarize the differences in the distributions of the responses to these questions. These means are presented in Table 2, where we also indicate the expectations with respect to the relative size of the

13 It is difficult to know what the few respond ents who chose interior least-preferred levels had in mind. It may be that specific items mentioned as allowed at one of the interior levels triggered a reaction strong enough to preven $t$ the respondent fro $m$ realizing that a level "beyond" the one in question would also allow (or disallow) that activity and others in addition. 
means in the different frames (the H columns). The differences in the means between the private frame and the committed frame correspond to a priori expectations in all cases and these differences are always statistically significant (though in one case only at a 5\% level). ${ }^{14}$ The directions of the differences in the means between the private and the public frames conform to a priori expectations five out of a possible eight times, though only three times is the inequality statistically significant.

Table 2. Mean Most- and Least-Preferred Levels by Frame.

\begin{tabular}{|c|c|c|c|c|c|c|}
\hline \multicolumn{2}{|c|}{ US (Radnor Lake) } & Public & H & Private & $\mathbf{H}$ & Committed \\
\hline \multirow[t]{2}{*}{ Most preferred } & Land & 2.97 & $>{ }^{* *}$ & 2.84 & $>^{* * *}$ & 2.50 \\
\hline & Lake & 2.98 & $(<)$ & 2.99 & $>^{* * *}$ & 2.44 \\
\hline \multirow[t]{2}{*}{ Least preferred } & Land & 3.29 & $<* * *$ & 3.68 & $<* * *$ & 4.16 \\
\hline & Lake & 3.57 & $<* * *$ & 3.82 & $<^{* * *}$ & 4.33 \\
\hline \multicolumn{7}{|c|}{ Denmark (Tokkekøb Hegn) } \\
\hline \multirow[t]{2}{*}{ Most preferred } & Land & 2.78 & $>$ & 2.72 & $>^{* * *}$ & 2.60 \\
\hline & Lake & 2.70 & $>$ & 2.64 & $>^{* * *}$ & 2.40 \\
\hline \multirow[t]{2}{*}{ Least preferred } & Land & 4.37 & $(>)$ & 4.31 & $<* * *$ & 4.49 \\
\hline & Lake & 4.58 & $(>)$ & 4.56 & $<* *$ & 4.67 \\
\hline
\end{tabular}

Notes: Parentheses indicate that the sign of the difference is opposite to that hypothesized. If the sign is correct but the difference is not significant, there are no stars. Two stars indicates significance at $5 \%$; three stars at $1 \%$.

The simple t-tests for differences of the means do not, however, take into account differences

14 The significance levels in Table 2 refer to a one sided test, e.g. looking at the mean of the least preferred lake levels, the committed mean in Denm ark (4.67) is statistically higher than the private mean (4.56) at a $5 \%$ level $(\mathrm{p}=0.046)$. However, these two means are not statistically different at a $5 \%$ level $(\mathrm{p}=0.091)$. 
in the socioeconomic characteristics of respondents. ${ }^{15}$ These characteristics can be included (and thereby controlled for) using discrete choice models for the most-preferred levels (ordered probit) and for the relative order of the most- and least-preferred levels (binary probit). In the latter model, the binary variable is defined as one if the most-preferred level is higher in intensity than the leastpreferred level and zero if the most-preferred is less intense than the least-preferred. Generally, we would expect the signs of the parameters in the probit models for the relative order of the most- and least-preferred levels to be similar to the parameters found in the ordered probit models for the mostpreferred levels, because of the way in which the binary variable has been defined. That is, a one implies a higher most-preferred level and a zero a lower one. ${ }^{16}$

Separate (ordered) probit models are estimated for the land index and the lake index. The results of these discrete choice models are summarized in Table 3 . The public and committed frames are included as explanatory variables (leaving the private frame as the base case). Information about which activities the respondents carry out in recreational areas are included as explanatory variables together with socioeconomic variables. The table reports the estimated coefficients attached to the

15 The test of the means should also be taken with a grain of salt because the means depend on the arb itrarily scaled values for the intensity index, e.g. 1, 2, 3, 4, 5. Only if the underlying latent (and unobserved) scales of respondents are equidistant, as is the scale we have chosen, will the test of the means be valid.

16 Since practically all the least preferred levels are either 1 or 5 it will generally be the value of the least preferred level that determines whether the least preferred level is lower or higher than the most preferred level. The results presented in Table 3 would therefore be very similar to a probit model for low versus high level for the least preferred intensity level, had one been estimated. 
frames, while only the signs of the effects ${ }^{17}$ of other variables are described (all estimated coefficients may be found in Appendix 2).

As expected, the committed frame seems to induce preferences for the less-intensive activity levels, i.e. respondents receiving the committed frame choose less-intensive levels as their mostpreferred and more-intensive as their least-preferred, as the coefficients on the committed frame dummy are negative in all eight regressions and statistically significant at either the $1 \%$ or $5 \%$ level in six of the eight. The coefficient for the public frame is positive (as expected) in six of the eight regressions, but only significant in four of these regressions. The public frame is positive and significant in three of the four U.S. regressions, but in only one of the four Danish regressions (and only at the $10 \%$ level).

Looking at the socioeconomic variables it appears that females generally prefer higher intensity levels, while older respondents typically prefer lower intensity levels. Both of these effects are more pronounced in the U.S. regressions than in the Danish ones. In both countries, respondents with higher levels of educational attainment prefer lower intensity levels. Income is never significant, perhaps because of collinearity with education. As expected, members of environmental organizations (NGO) prefer lower use levels. In the U.S., respondents living in census block groups

17 Variables available for the U.S. but not the Danish regressions: (BLHIAREA)- - residence in a census tract with relatively high percentages of black or Hispanic residents: Variables available for the Danish but not the US regressions are: (SINGLE)- - respondent is single; and (SELF EMP)- -respon dent is self-employed. Not all available activity variables were included in the final regressions reported in Table 3, only those with coefficients significant at at least the $10 \%$ level in at least one of the four regressions. Finally, Table 3 represents an editing of the full regres sions (Appendix tables A.2.1 and A.2.2) to stress comparability across countries. 
with higher percentages of blacks and/or Hispanics prefer higher intensity levels. In Denmark, selfemployed respondents prefer lower intensity levels.

Table 3. Effects of frames and characteristics on preferred intensity levels.

\begin{tabular}{|c|c|c|c|c|c|c|c|c|}
\hline \multirow{3}{*}{$\begin{array}{l} \\
\text { Variable } \\
\text { Frames }\end{array}$} & \multicolumn{4}{|c|}{ United States } & \multicolumn{4}{|c|}{ Denmark } \\
\hline & \multicolumn{2}{|c|}{$\begin{array}{c}\text { Most preferred } \\
\text { levels }\end{array}$} & \multicolumn{2}{|c|}{$\begin{array}{l}\text { Order of most and } \\
\text { least preferred levels }\end{array}$} & \multicolumn{2}{|c|}{$\begin{array}{l}\text { Most preferred } \\
\text { levels }\end{array}$} & \multicolumn{2}{|c|}{$\begin{array}{l}\text { Order of most and } \\
\text { least preferred levels }\end{array}$} \\
\hline & Land & Water & Land & Water & Land & Water & Land & Water \\
\hline $\begin{array}{l}\text { PUBLIC } \\
\text { (t-value) }\end{array}$ & $\begin{array}{c}0.16 \\
(2.44)^{* *}\end{array}$ & $\begin{array}{l}-0.01 \\
(0.10)\end{array}$ & $\begin{array}{c}0.30 \\
(3.52)^{\star * *}\end{array}$ & $\begin{array}{c}0.19 \\
(2.19)^{* *}\end{array}$ & $\begin{array}{c}0.11 \\
(1.75)^{\star}\end{array}$ & $\begin{array}{c}\mathbf{0 . 0 9} \\
(1.55)\end{array}$ & $\begin{array}{l}-0.04 \\
(0.44)\end{array}$ & $\begin{array}{c}\mathbf{0 . 0 3} \\
(0.33)\end{array}$ \\
\hline $\begin{array}{l}\text { COMMITTED } \\
\text { (t-value) }\end{array}$ & $\begin{array}{c}-0.17 \\
(2.71)^{\star * *}\end{array}$ & $\begin{array}{c}-0.29 \\
(4.73)^{\star * *}\end{array}$ & $\begin{array}{c}-0.13 \\
(1.47)\end{array}$ & $\begin{array}{c}-0.27 \\
(3.03)^{\star * *}\end{array}$ & $\begin{array}{c}-0.14 \\
(2.30)^{\star *}\end{array}$ & $\begin{array}{c}-\mathbf{0 . 2 6} \\
(4.27)^{\star * *}\end{array}$ & $\begin{array}{c}-0.18 \\
(2.03)^{\star \star}\end{array}$ & $\begin{array}{l}-0.15 \\
(1.44)\end{array}$ \\
\hline \multicolumn{9}{|l|}{$\begin{array}{l}\text { Socioeconomic } \\
\text { characteristics: }\end{array}$} \\
\hline FEMALE & +++ & $(+)$ & +++ & ++ & $(+)$ & $(+)$ & $(+)$ & $(-)$ \\
\hline AGE & --- & --- & $(+)$ & $(-)$ & $(-)$ & --- & $(-)$ & $(-)$ \\
\hline EDUCATION & --- & -- & --- & -- & $(-)$ & $(-)$ & -- & -- \\
\hline INCOME & $(-)$ & $(-)$ & $(-)$ & $(-)$ & $(-)$ & $(-)$ & $(-)$ & $(+)$ \\
\hline KIDS & $(+)$ & $(-)$ & $(+)$ & $(+)$ & $(-)$ & + & $(+)$ & $(+)$ \\
\hline NGO (GREEN) & -- & - & - & - & $(-)$ & --- & $(-)$ & -- \\
\hline BLHIAREA & +++ & +++ & +++ & +++ & na & na & na & na \\
\hline SINGLE & na & na & na & na & - & $(+)$ & $(-)$ & $(+)$ \\
\hline SELFEMP & na & na & na & na & - & -- & $(-)$ & $(-)$ \\
\hline DISTANCE & $(+)$ & +++ & ++ & $(+)$ & na & na & na & na \\
\hline VISITAREA & - & -- & - & - & +++ & $(-)$ & $(-)$ & $(-)$ \\
\hline \multicolumn{9}{|l|}{ out in nature } \\
\hline HIKE/HIKEOFTEN & - & na & - & na & - & $(-)$ & $(-)$ & $(-)$ \\
\hline BIRDWATCH & na & - & na & - & $(-)$ & -- & - & --- \\
\hline DOG & +++ & na & $(+)$ & na & +++ & na & +++ & na \\
\hline HORSE & +++ & na & ++ & na & ++ & na & $(-)$ & na \\
\hline HUNTING & $(+)$ & na & ++ & na & - & na & $(-)$ & na \\
\hline CANOE & na & $(-)$ & na & $(-)$ & na & +++ & na & ++ \\
\hline MOTORBOAT & na & $(+)$ & na & $(+)$ & na & na & na & na \\
\hline FISHING & na & +++ & na & +++ & na & $(+)$ & na & $(+)$ \\
\hline SWIMMING & na & +++ & na & $(+)$ & na & + & na & $(-)$ \\
\hline
\end{tabular}


Note: Three, two and one stars/plus/minus indicate significance at respectively $1 \%, 5 \%$ and $10 \%$. (Sign of non-significant parameters shown in parens.) In model for ordering of most and least preferred, a one corresponds to most preferred level > least preferred; zero indicates the opposite "shape". "na" means the variable was not applicable or not available. See text for details.

In the U.S. respondents who often visit Radnor Lake (VISITAREA) prefer lower activity levels, while those who live farther away (DISTANCE) prefer higher levels. It seems reasonable that frequent visitors and those living closest to Radnor Lake prefer lower use levels because they are more likely to be affected by congestion in the park. (People never visiting the park or living far from the area need not worry about congestion effects). A similar pattern was not found in the Danish data set, where respondents who had visited the area preferred higher intensity levels (for most preferred land intensity index). ${ }^{18}$ As a potential explanation for this divergence it should be noted that the actual intensity of use of the RLNA appears to be higher than the use intensity of TH. It is therefore likely that respondents in the U.S. (and specially respondents often visiting or living close to the area) gave more consideration to potential crowding, because they are more likely to have experienced the adverse effects of such crowding.

Turning to the activities carried out by the respondents when they visit forested recreational areas, it appears that dog owners and people who go horseback riding prefer higher intensity levels DISTANCE affects the reliability of the coefficient estimates. 
(for the land index). This finding very likely reflects the fact that dogs and horseback riding are restricted at the lower intensity levels. For the lake index, the same type of effect seems to apply to respondents who go fishing and swimming, as they also prefer higher intensity levels. Finally, respondents who have engaged in activities best enjoyed in more "unspoilt" natural areas (i.e. going hiking or birdwatching) prefer lower intensity levels.

\subsection{Interaction of framing and familiarity}

In the discrete models estimated above, it has implicitly been assumed that the effect of a frame is the same for all respondents receiving that frame. A comparison of framing effects for different groups of respondents can be carried out by splitting the sample and estimating separate discrete choice models for each group. In Table 4, we compare the base-case, pooled sample coefficients of the frame variables with those for respondents who are familiar with the area (respondents that have visited the area within the last year) and those for respondents not familiar with the area (respondents who have not visited the area within the last year). In the regressions for the split samples, we have included the same variables as before (with the exception of VISITAREA), but, for ease of comparison, we only show the parameters (and their t-values) for the frames. (Again, the private frame is the base case). 
Table 4. Interaction of Framing and Familiarity

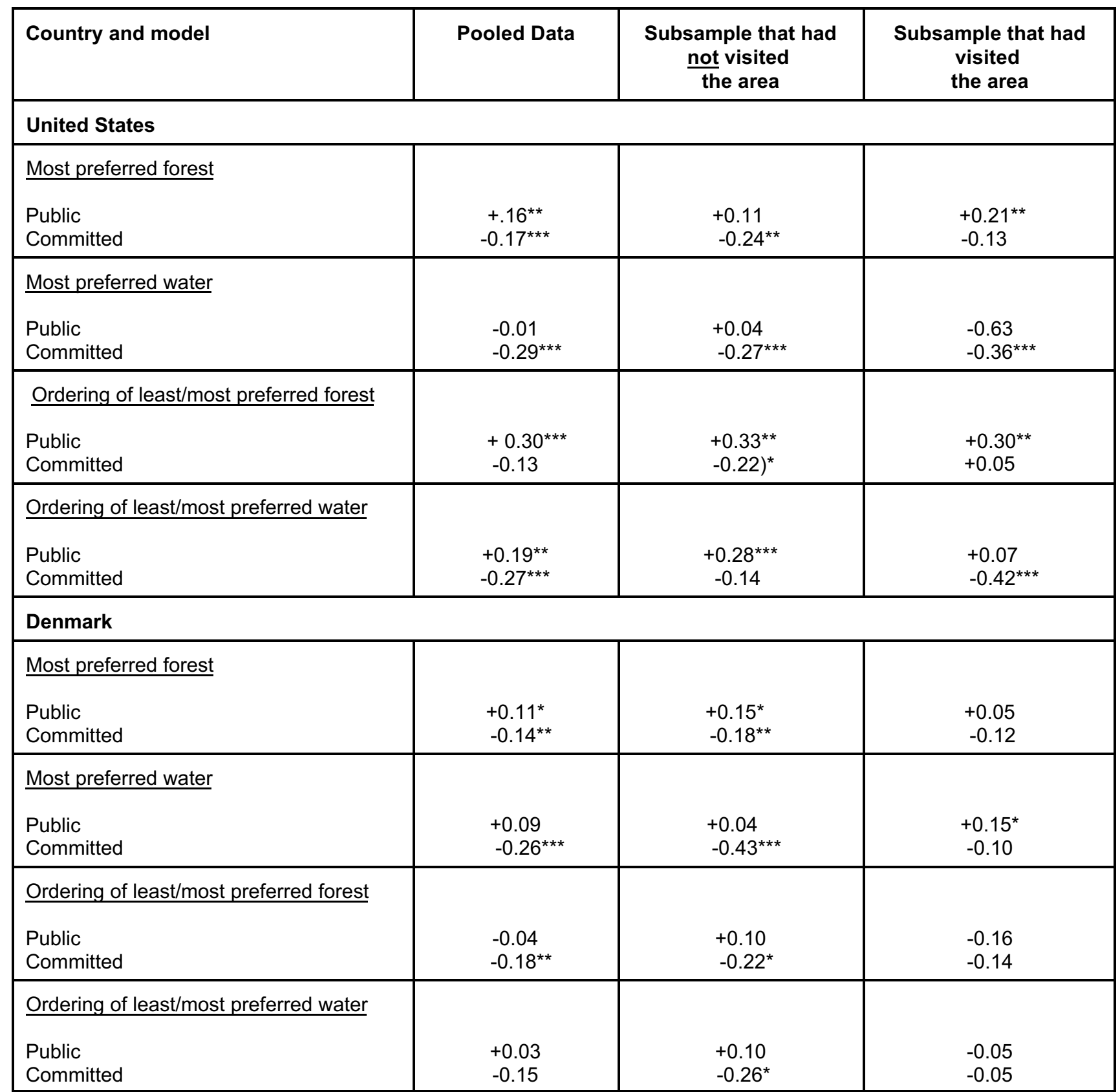

Note: $\quad$ Three, two and one stars indicate significance respectively at $1 \%, 5 \%$ and $10 \%$.

The pattern that emerges is interesting, for it suggests that respondents who have not visited the park in question are more likely than those who have to be able to call up one or the other public 
preference version when subjected to our triggering paragraphs. Thus, comparing the results from the pooled (full sample) data in column 1 with that for non visitors in column 2, we see that in each case 10 of 16 coefficients on the frame dummies are significant at the $10 \%$ level or better. For eight coefficients, both those for the full sample and those for the non-visitors are significant, five at the same level. For those who had visited only five of 16 coefficients in the equations for the visitors sub sample are significant. Only one of these "washes out" when the sub samples are pooled.

Why should such a pattern arise? One likely explanation is the effect of habit and familiarity. Users know the parks as they are now managed and probably for the most part approve of the existing rules. They may find it hard to relate to suggested changes, no matter what the frame in which they are presented, and so are insensitive to our "treatments." A somewhat different interpretation relates to the public versus private nature of the good for users and non-users. For a non-user, the area has a more public-good nature, than for users. In that light, it appears that it is easier to motivate expression of nonprivate preferences for pure public goods as compared with semi-public goods. The stronger framing effects for non-users as compared with users coincide with the finding in the study of Ajzen et al. $(1996) .{ }^{19}$

In the following section we investigate respondents' own statements about the concerns triggered by the different frames. We thus take a different route examining whether or not the frame

19 A comparison of the size of the effect of the frames has also been carried out for gender and for respondents with high/low level of education. With respect to gender it appears that women in Denmark but men in the U.S. re spond more strongly to the committed frame. In the U.S., (weak) results indicate that those with lower levels of educational attainment are influenced more by the committed frame, while tho se with higher levels react more strongly to the public frame. In Denmark, no clear pattern could be found with respect to the level of ed ucational attainment. 
triggered the intended motivation in the respondents.

\subsection{Self-reported concerns and frames}

Responses to the questions about what the respondents were considering when they answered the activity level questions should be interpreted cautiously for at least two reasons. First, respondents may, on some level, interpret their answers to these questions as a barometer of how "good" a person they are, and thus, be tempted to overstate their concern for others or for the environment. Second, some people may exhibit concern for others or for nature, without everbeing consciously aware of this concern. Having noted these cautions, in the analysis that follows, we take the statements of self-reported concern at face value, though it should be noted that our focus is not on the absolute level of concern, but on the relationship between the frames and the self-reported concerns.

In the U.S. version of the questionnaire, respondents were simply asked to choose one from among the following four as best describing their primary consideration in answering the activity level questions: (1) yourself and your family; (2) other people who might visit the area, (3) plants and animals in the area or (4) future generations. Based on their responses, dummy variables were created for each category of concern to indicate whether or not the respondent considered this category as the most important. In the Danish version, respondents were asked to assign "importance weights" ranging from 1 to 5 to the same four categories. For purposes of comparison to the U.S. results, dummy variables have been produced from these importance weights, by first calculating the "mean concern" for each individual. Then a dummy was created for each "concern" taking the value one if the weight assigned to 
that concern exceeded the average and zero if it was less than the average. Thus, for respondents allocating the same level of concern to all categories, these dummies would all be zero. The entire distribution of responses to these questions can be found in Bjørner, et al.(2000).

A comparison of the distribution of these responses by frame (not shown here) suggests that the frames have, at best, a limited impact on the self-reported concern. Here, the effects of the frames on self-reported concern are investigated more formally in probit models, where the concern dummy variables are the endogenous variables. Again, the frames are included as explanatory variables (leaving the private frame as the base case) together with socioeconomic variables. The results of these regressions are summarized in Table 5 (to ease comparison, the table only includes the sign and level of significance for the socioeconomic variables) ${ }^{20}$.

Table 5. Effects of frames on self-reported concern (probit models)

\begin{tabular}{|c|c|c|c|c|c|c|c|c|}
\hline & & Unite & States & & & & Imark & \\
\hline & SELF & OTHER & NATURE & FUTURE & SELF & OTHER & NATURE & FUTURE \\
\hline Frames & & & & & & & & \\
\hline $\begin{array}{l}\text { PUBLIC } \\
\text { (t-value) }\end{array}$ & $\begin{array}{c}\mathbf{0 . 0 1} \\
(0.09)\end{array}$ & $\begin{array}{c}-0.05 \\
(0.46)\end{array}$ & $\begin{array}{c}-\mathbf{- 0 . 1 5} \\
(1.51)\end{array}$ & $\begin{array}{l}\mathbf{0 . 2 2} 2^{\star *} \\
(2.12)\end{array}$ & $\begin{array}{c}\mathbf{0 . 0 2} \\
(0.32)\end{array}$ & $\begin{array}{c}-0.15 \\
(1.44)\end{array}$ & $\begin{array}{c}\mathbf{0 . 0 3} \\
(0.39)\end{array}$ & $\begin{array}{c}\mathbf{0 . 0 0} \\
(0.02)\end{array}$ \\
\hline $\begin{array}{l}\text { COMMITTED } \\
\text { (t-value) }\end{array}$ & $\begin{array}{l}-0.24^{* * *} \\
(2.79)\end{array}$ & $\begin{array}{l}-0.04 \\
(0.44)\end{array}$ & $\begin{array}{l}-0.04 \\
(0.48)\end{array}$ & 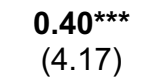 & $\begin{array}{l}-0.01 \\
(0.18)\end{array}$ & $\begin{array}{c}-0.22^{* *} \\
(2.09)\end{array}$ & $\begin{array}{c}\mathbf{0 . 2 1} 1^{* * *} \\
(2.87)\end{array}$ & $\begin{array}{c}\mathbf{0 . 1 0} \\
(1.36)\end{array}$ \\
\hline $\begin{array}{l}\text { Socioeconom } \\
\text { characteristic }\end{array}$ & & & & & & & & \\
\hline FEMALE & $(+)$ & ++ & $(-)$ & -- & --- & $(+)$ & $(-)$ & ++ \\
\hline AGE & --- & +++ & $(-)$ & ++ & --- & - & --- & $(+)$ \\
\hline EDUCATION & + & $(-)$ & $(-)$ & $(-)$ & +++ & + & - & -- \\
\hline INCOME & +++ & $(-)$ & --- & $(+)$ & $(-)$ & $(-)$ & $(+)$ & $(+)$ \\
\hline
\end{tabular}

20 A more detailed description of these regressions may be found in Bjørner et al. (2000). 


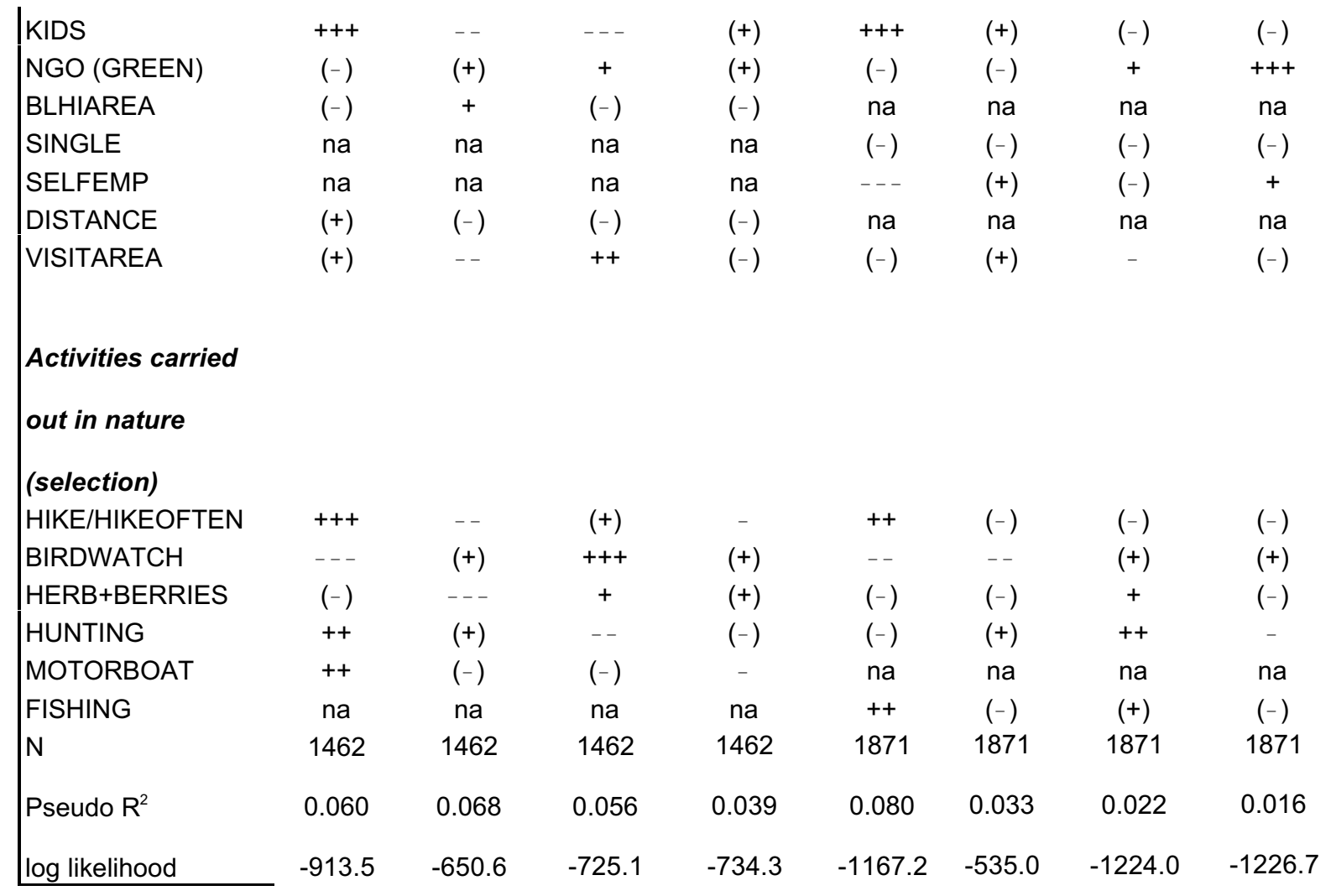

Note: Three, two and one stars/plus/minus indicate significance at $1 \%, 5 \%$ and $10 \%$, respectively(sign of non-significant parameters shown in parentis)

Focusing on the effect of the frames on self-reported concerns, it appears that the frames did, in some instances, have a significant influence on this concern. Specifically, the public frame had a significant positive effect on the likelihood that a U.S. respondent indicated future generations to be his or her primary consideration. The committed frame had a significant negative effect on the likelihood that a U.S. respondent would choose "yourself and your family" as her most important consideration and a significant positive effect on the likelihood that a U.S. respondent would choose future generations as her primary consideration. In Denmark, the committed frame had a significant negative effect on the likelihood that a respondent would strongly consider other people and a significant positive effect on the 
likelihood that they would strongly consider the area's flora and fauna. In all five of these instances the sign of the significant parameter conforms to a priori expectations. It is noteworthy, however, that respondents exposed to the public frame did not state a higher concern for other people than the respondents to the private frame. (Actually a negative, but insignificant, sign was obtained in both the U.S. and Denmark for the public frame in the probit model for concern about other people.)

Some of the other variables also exhibited interesting effects on self-reported concern. For example, females in Denmark are more likely to claim to consider future generations, while U.S. females are less likely. Not surprisingly, both U.S. and Danish respondents with children are more likely to consider themselves and their family when answering, while the opposite is true for older respondents they are less likely to consider themselves when answering. What is surprising, however, is that respondents with higher levels of educational attainment were more likely to consider themselves in answering, as were those who participate in outdoor activities such as hiking, birdwatching, and motor boating (in the U.S.) or fishing (in Denmark). Conforming to a priori expectations, members of environmental organizations (NGO) were more likely to consider nature in answering the questions, as were respondents who pick herbs or berries in both countries and hunters in Denmark - presumably for other reasons than members of environmental organizations. U.S. hunters were less likely to consider nature and more likely to consider self and family in answering the questions. Finally, U.S. respondents who had recently visited the area were more likely to consider nature while Danish visitors were less likely.

In the regressions summarized above in Table 3, the Public and Committed frames were 
included as explanatory variables, along with socioeconomic and forest activity variables, to explain the respondents' choice of most-preferred activity levels. Similar regressions have been carried out where the frames were replaced by the dummy variables representing self-reported concerns. The effect of the self-reported concern on the most preferred levels are summarized in Table 6 (the same socioeconomic and activity variables that were included in the "original" regressions reported in Appendix Two were also included, but the parameters to these variables are not reported). ${ }^{21}$

Table 6. Most preferred intensity levels and self-reported concern

\begin{tabular}{|c|c|c|c|c|c|c|c|c|}
\hline & & & S. & & & Denr & nark & \\
\hline & & Drdered & Probit for & & & rdered $\mathrm{F}$ & robit for & \\
\hline & & ost prefe & rred levels & & & st prefe & rred levels & \\
\hline & Land ir & $\operatorname{dex}$ & Water i & ndex & Land in & $\operatorname{dex}$ & Water is & idex \\
\hline Variable & Coefficient & t-value & Coefficient & t-value & Coefficient & t-value & Coefficient & $\mathrm{t}$-value \\
\hline Self-reported & & & & & & & & \\
\hline YOURSELF & (base c & ase) & (base $c$ & ase) & $0.31^{* * *}$ & 5.64 & $0.45^{\star \star *}$ & 7.71 \\
\hline OTHER PEOPLE & 0.12 & 1.46 & 0.08 & 0.97 & $0.31^{* * *}$ & 3.33 & $0.31^{* \star *}$ & 3.27 \\
\hline NATURE & $-0.63^{\star * *}$ & 8.03 & $-0.91^{* \star *}$ & 11.34 & $-0.26^{* * *}$ & 4.46 & $-0.44^{* * *}$ & 7.26 \\
\hline FUTURE GENERATIONS & $-0.49^{* * *}$ & 6.34 & $-0.52^{* * *}$ & 6.72 & -0.06 & 1.04 & 0.06 & 1.07 \\
\hline $\mathrm{N}$ & 143 & & 143 & & 1849 & & 1851 & \\
\hline Pseudo $R^{2}$ & 0.08 & & 0.12 & & 0.036 & & 0.04 & \\
\hline
\end{tabular}

21 The estimated parameters to the socioeconomic and the activity variables in the regressions where the concern variables replace the frame variables generally have the same sign and size as in the regressions with the frame variables, which are reported in Appendix 2 (signs/size only ch ange for variables that were insignificant in the frame regressions). The pseudo $\mathrm{R}^{2}$ is higher in the regressions where the concern variables have replaced the frame variables. Table 6 only reports the results of the ordered probit for most preferred levels, but the same results (qualitatively) were obtained in probit models for the relative order of the most and least preferred intensity levels. 
Note: Three, two and one stars indicate significance at respectively $1 \%, 5 \%$ and $10 \%$.

In the U.S. model, the respondents who expressed high concern for themselves and their family served as the base case. Reassuringly, the U.S. respondents asserting either that nature or that future generations was their primary consideration preferred lower intensity levels than those whose primary consideration was themselves and their family (NATURE and FUTURE GENERATIONS have significant negative signs). However, respondents claiming to be primarily concerned about other people do not seem to prefer higher intensity levels than respondents whose primary consideration was themselves and their family (sign on OTHER PEOPLE is positive but insignificant). This is consistent with the results in Table 5, in which the public frame had a small effect on the reported consideration of the respondent.

For Danish respondents similar results are found, though now those respondents who failed to indicate a relatively high concern to any of the different categories are the base case. Thus, respondents with a high concern for nature prefer lower intensity levels. On the other hand, the signs for OTHER PEOPLE are both positive and significant, but then so are the signs for the variables indicating a relatively strong concern for the respondent and his/her family. In fact, the coefficient on the variable indicating a relatively strong concern for self and family is the same size or larger than the coefficient on the variable indicating a relatively strong concern for other people in both of the Danish regressions. Thus, the analysis of the respondents' self-identified concern and the preferred intensity levels suggests 
that it may be difficult to distinguish between the expression of private preferences and public preferences in both the U.S. and Denmark. This difficulty may explain why the public frame had no clear effect on the expressed preferences.

\section{Summary and conclusion}

Some other studies finding support for altruistic behaviorhave used only one sample and more directly asked people about the motivation for their actions. However these "one-sample studies" may be biased if people respond by guessing what they think they ought to want instead of what they do want for themselves. We have tried to remove, or at least reduce, this problem by supplying only one set of motives in each of the frames. So each respondent sees only one "trigger." In addition, that trigger constituted a very small part of the survey, keeping the material available for preference construction small.

It appears that the committed frame was generally successful in triggering expressions of committed preferences, where the commitment was apparently to "unspoilt" nature. The public frame also

in some cases yielded responses as expected, but the results overall were not as strong as for the committed frame. These conclusions were derived from visual examination of the distributions for the most and least preferred intensity levels; from the means of these distributions; and finally from the probit models, with the frames entering as explanatory variables. There does not appear to be an enormous difference between the extent to which Danes and Americans were affected by the Committed and Public frames, but the difference observed-- more statistically significant coefficients from the U.S. 
study- - is interesting because quite unexpected. The overall result may imply that it is more difficult to make people care about others than about the environment. On the other hand, it may only mean that we were more fortunate in ourchoice of wording used to try to trigger the committed preferences, compared with that for the public frame (i.e. that the wording was "stronger" for the committed frame).

Furthermore, it may also be the case that our a priori hypothesis about the form of the expressions of public altruism was too simple (or even wrong). Our expectation was that those respondents who were asked to think about others, would choose higher intensity levels, because these higher intensity levels would, at least implicitly, satisfy a greater range of tastes and thus allow more people to use the natural area for a wider array of purposes. It could, however, be argued that the opposite is true, i.e., that the publicly- or altruistically-motivated person who thinks in terms of external effects might be paternalistic and opt for lower intensity levels in order to protect other users from the noise and general disturbance that accompany high use levels. This same person might himself even want to use a vehicle in the forest (high intensity level), but as a public (paternalistic) altruist he might vote for rules that would make that impossible in order to protect others. Or, taking a slightly different tack, one might argue that people want for others what they want for themselves (and do not trouble themselves with problems of logical consistency, such as the impossibility of having low use levels while serving "everyone"). In this case it would be difficult or impossible to reveal any differences in private and public preferences, at least in the way we have pursued here. Such disregard of the implications of serving many people would be consistent with the results reported in Table 6, where preferred intensity levels were regressed on self-reported concerns (and other variables). 
Finally, the lack of substantial and consistent differences in patterns of response to the frames as between Danes and Americans surprised us. We expected the Danish respondents to be, at the very least, more easily triggered to express public and committed preferences. The popular cultural image of all the Scandinavian societies suggests strong streaks of caring, for other people as well as for nature. The U.S., on the other hand, is popularly seen as the heartland of selfish individualism. It appears from our results that both nations' citizens, when consulting their own preferences, prefer low but not primitive management intensity; that both groups can easily be pushed to "commit" to nature; but are not so easily made to adopt "sympathetic" altruism.

There remains, in any case, much room for additional empirical exploration of preference mutability, but we believe the technique used here, focusing on patterns of preference for described policies in the absence of money considerations, is a promising technique for undertaking this. 


\section{References}

Ajzen, Icek, Thomas C. Brown and Lori H. Rosenthal (1996): Information Bias in Contingent Valuation: Effects of Personal Relevance, Quality of Information, and Motivational Orientation. Journal of Environmental Economics and Management. 30, p. 43-57.

Andreoni, James, 1988. "Privately Provided Public Goods in a Large Economy: The Limits of Altruism," Journal of Public Economics. 35(1); 57-73.

Andreoni, James, 1995. "Cooperation in Public Goods Experiments: Kindness or Confusion?" American Economic Review. 85(4); 891-904.

Arrow, Kenneth J., 1963. Social Choice and Individual Values. New York, NY: John Wiley \& Sons.

Beckerman, Wilfred and Joanna Pasek; "Plural Values and Environmental Valuation." Environmental Values 6:65-86.

Bjørner et al. 1998. "Triggering Expressions of Public as Opposed to Private Preferences in the U.S. and Denmark." Paper presented at the 1998 World Congress of Environmental and Resource Economists in Venice, Italy.

Bjørner, et al. 2000. "Public and Private Preferences for Environmental Quality in Denmark." SØM publication no. 38 (AKF research report), Copenhagen.

Bohm 1994 A “'CVM Spells Responses to Hypothetical Questions,” Natural Resources Journal 34(1), 3750 .

Bohm 1994'. "Behaviour under Uncertainty without Preference Reversal: A Field Experiment," Empirical Economics 19(2), 185-200.

Brown, Thomas C., Patricia A. Champ, Richard C. Bishop, and Daniel McCollum, 1996. "Which Response Format Reveals the Truth About Donations to a Public Good?" Land Economics. 72(2); 152-66.

Fehr, Ernst, Georg Kirchsteiger, and Arno Riedl, 1993. "Does Fairness Prevent Market Clearing? An Experimental Investigation", Quarterly Journal of Economics. 108(2); 437-60.

Fischhoff, Baruch, 1991. "Value Elicitation: Is There Anything There?", American Psychologist. 46(8); 835-47.

Forsythe, Robert, Joel L. Horowitz, N.E. Savin, and Martin Sefton, 1994. "Fairness in Simple Bargaining 
Experiments", Games and Economic Behaviour. 6(3); 347-69.

Harsanyi, John C., 1955. "Cardinal Welfare, Individualistic Ethics, and Interpersonal Comparisons of Utility", Journal of Political Economy. August; 309-21.

Gregory, Robin, Sarah Lichtenstein, and Paul Slovic, 1993. "Valuing Environmental Resources: A Constructive Approach," Journal of Risk and Uncertainty 7: 177-197.

Hudson, John, and Philip Jones, 1995. "The Importance of the Ethical Voter: An Estimate of Altruism", in Stefano Zamagni, (ed), The Economics of Altruism. Aldershot, U.K.: Edward Elgar; 196-205.

Johansson, Olof, 1997. "Optimal Pigovian Taxes under Altruism ". Land Economics 73(3): p.297-308.

Johansson-Stenman, Olof, 1998. "The Importance of Ethics in Environmental Economics with a Focus on Existence Values". Environmental and Resource Economics. 11 (3-4): 429-42.

Johansson-Stenman, Olof, 1999. Environmental Regulation in the Presence of Interdependent and Context-Dependent Preferences and Social Norms. (unpublished paper). Department of Economics, Göteborg University.

Kolm, Serge-Christophe, 1983. "Altruism and Efficiency", Ethics. October; 18-65.

Kolm, Serge-Christophe, 1994. "The Meaning of 'Fundamental Preferences'", Social Choice and Welfare. 11(3); 193-98.

Lapiere, R.T., 1934. “Attitudes vs. Actions”, Social Forces 13:230-237.

McConnell, K.E., 1997. Does Altruism Undermine Existence Value? Journal of Environmental Economics and Management. 32; 22-37.

Milgrom, Paul, 1993. "Is Sympathy an Economic Value? Philosophy, Economics and the Contingent Valuation Method" in Hausman, Jerry A. (ed) Contingent Valuation: A Critical Assessment. Contributions to Economic Analysis, vol. 220. Elsevier Science, New York.

Prasniker, Vesna, and Alvin E. Roth, 1992. "Considerations of Fairness and Strategy: Experimental Data from Sequential Games", Quarterly Journal of Economics. 107(3); 865-88.

Russell, Clifford S., Virginia Dale, Junsoo Lee, Molly Hadley Jensen, Michael Kane and Robin Gregory, 2001. Experimenting with Multi-attribute Utility Survey Methods in a Multi-dimensional Valuation Problem. Forthcoming In Ecological Economics. 
Sagoff, Mark, 1988. Cambridge Studies in Philosophy and Public Policy Series.Cambridge; New York and Melbourne, Cambridge University Press, 1988, pages x, 271.

Sen, Amartya, 1977. "Rational Fools: A Critique of the Behavioral Foundation of Economic Theory", Philosophy and Public Affairs. 6(4); 317-44.

Slovic, Paul, 1995. "The Construction of Preference", American Psychologist. 50(5); 364-71.

Stern, Paul C., Thomas Dietz, and Linda Kalof, 1993. "Value Orientations, Gender, and Environmental Concern," Environment and Behavior. 25; 322-348.

Stern, Paul C., and Thomas Dietz, 1994. “The Value Basis of Environmental Concern,” Journal of Social Issues. 50(3); 65-84.

Weaver, Robert D., 1996. "Prosocial Behavior: Private Contributions to Agriculture's Impact on the Environment", Land Economics. 72(2); 231-47. 


\section{Appendix 1 Intensity Index}

Below is the text used to describe the intensity indexes. In addition to this text, two illustrative photographs were also included to describe each intensity level.

\section{Table A1.1 Text used to describe the intensity index}

\begin{tabular}{|c|c|c|}
\hline Level & Land activity & Water ac tivity \\
\hline $\begin{array}{l}\text { Level } 1 \text { - } \\
\text { Fewest } \\
\text { activities }\end{array}$ & $\begin{array}{l}\text { - only walking/hiking allowed } \\
\text { - no groom ing of trails } \\
\text { - no dogs } \\
\text { - no horses, bikes, motor bikes, ATVs or cars } \\
\text { - no restrooms } \\
\text { - no picnic tables } \\
\text { - no road }\end{array}$ & $\begin{array}{l}\text { - No recreation in or on the lake (no fish- } \\
\text { ing, boating or swimming) } \\
\text { - Undisturbed habitat for fish, reptiles, } \\
\text { waterfowl, beaver }\end{array}$ \\
\hline $\begin{array}{l}\text { Level } 2 \text { - } \\
\text { A few more } \\
\text { activities }\end{array}$ & $\begin{array}{l}\text { - some groomed trails } \\
\text { - dogs permitted on leash } \\
\text { - no horses, bikes, motor bikes, ATVs or cars } \\
\text { - a few restrooms } \\
\text { - a few picnic tables } \\
\text { - no road }\end{array}$ & $\begin{array}{l}\text { - a few canoes and rowboats available for } \\
\text { rent } \\
\text { - no fishing from boat or bank } \\
\text { - no private boats or canoes } \\
\text { - no swimming }\end{array}$ \\
\hline $\begin{array}{l}\text { Level } 3 \text { - } \\
\text { More } \\
\text { activities }\end{array}$ & $\begin{array}{l}\text { - most trails groomed } \\
\text { - dogs allowed } \\
\text { - horse-back riding on special horse trails } \\
\text { - bikes allowed on som e trails } \\
\text { - picnic and rest room facilities can handle } \\
\text { small groups } \\
\text { - road opened for cars }\end{array}$ & $\begin{array}{l}\text { - more can oes and rowboats plus small sail } \\
\text { boats for rent } \\
\text { - fishing allowed from rented boats and } \\
\text { canoes, with state licence } \\
\text { - private canoes allowed } \\
\text { - no boat motors of any kind } \\
\text { - no swimming }\end{array}$ \\
\hline $\begin{array}{l}\text { Level } 4 \text { - } \\
\text { Even more } \\
\text { activities }\end{array}$ & $\begin{array}{l}\text { - all trails groomed } \\
\text { - dogs allowed } \\
\text { - horse-back riding on s pecial trails } \\
\text { - bikes allowed on som e trails } \\
\text { - picnic and rest room fac ilities can hand le } \\
\text { large groups } \\
\text { - car road extended to scenic overlook on a } \\
\text { hill }\end{array}$ & $\begin{array}{l}\text { - canoes, rowboats, small sailboats for rent } \\
\text { - fishing allowed from boat or bank } \\
\text { - private can oes and sm all fishing boats } \\
\text { allowed } \\
\text { - quiet electric motors allowed } \\
\text { - small swimming area with beach and flo- } \\
\text { ats }\end{array}$ \\
\hline $\begin{array}{l}\text { Level } 5 \text { - } \\
\text { Most } \\
\text { activities }\end{array}$ & $\begin{array}{l}\text { - all trails groomed } \\
\text { - dogs allowed } \\
\text { - horse-back riding on special trails } \\
\text { - biking, motor biking, and ATV use on some } \\
\text { trails } \\
\text { - picnic and rest room facilities can handle } \\
\text { large groups } \\
\text { - second paved scenic overlook developed } \\
\text { - restaurant/café/coffee shop }\end{array}$ & $\begin{array}{l}\text { - canoes, rowboats, small sailboats for rent } \\
\text { - fishing allowed from bank or boat } \\
\text { - private can oes and sm all fishing boats } \\
\text { allowed } \\
\text { - jet skis available for rent } \\
\text { - small boat dock/marina } \\
\text { - swimming area expanded; snack bar } \\
\text { added }\end{array}$ \\
\hline
\end{tabular}

Note: These are the versions from the Nashville survey. The obvious changes were made to translate to the Danish site, but an effort was made to keep the "message" the same in each. 


\section{Appendix 2 Models for the most and least preferred intensity index}

\section{Table A2.1 Regression of framing effects in U.S.}

\begin{tabular}{|c|c|c|c|c|c|c|c|c|}
\hline \multirow[b]{3}{*}{ Variable } & \multicolumn{4}{|c|}{ Ordered Probit for most preferred levels } & \multicolumn{4}{|c|}{$\begin{array}{l}\text { Probit model for relative order of } \\
\text { most and least preferred levels }\end{array}$} \\
\hline & \multicolumn{2}{|c|}{ Land index } & \multicolumn{2}{|c|}{ Water index } & \multicolumn{2}{|c|}{ Land index } & \multicolumn{2}{|c|}{ Water index } \\
\hline & Coefficient & $\mathrm{t}$-value & Coefficient & t-value & Coefficient & t-value & Coefficient & t-value \\
\hline PUBLIC & 0.16 & $2.44^{* *}$ & -0.01 & -0.10 & 0.30 & $3.52^{* * *}$ & 0.19 & $2.19^{* *}$ \\
\hline COMMITTED & -0.17 & $-2.71^{* *}$ & -0.29 & $-4.73^{\star * *}$ & -0.13 & -1.47 & -0.27 & $-3.03^{* * *}$ \\
\hline FEMALE & 0.18 & $3.25^{\star * *}$ & 0.07 & 1.38 & 0.32 & $4.43^{* * *}$ & 0.17 & $2.24^{\star *}$ \\
\hline AGE & -0.08 & $-2.89^{* * *}$ & -0.09 & $-3.22^{* \star *}$ & 0.004 & 0.12 & -0.04 & -0.99 \\
\hline EDUCATION & -0.05 & $-2.92^{* * *}$ & -0.03 & $-1.98^{* *}$ & -0.06 & $-3.11^{* * *}$ & -0.06 & $-2.82^{* * *}$ \\
\hline INCOME & -0.01 & -0.47 & -0.03 & -1.48 & -0.02 & -0.68 & -0.03 & 1.32 \\
\hline KIDS & 0.02 & 0.25 & -0.06 & -0.99 & 0.08 & 1.02 & 0.01 & 0.17 \\
\hline BLHIAREA & 0.01 & $4.78^{* * *}$ & 0.01 & $5.82^{* \star \star}$ & 0.01 & $6.33^{\star \star *}$ & 0.01 & $5.10^{* * *}$ \\
\hline DISTANCE & 0.02 & 1.34 & 0.03 & $3.00^{* * *}$ & 0.03 & $2.35^{* *}$ & 0.02 & 1.47 \\
\hline VISITSOME & -0.35 & $-5.84^{* * *}$ & -0.59 & $-9.9^{* * *}$ & -0.33 & $-4.19^{\star * *}$ & -0.58 & $-7.57^{\star * *}$ \\
\hline VISITOFTEN & -0.67 & $-7.60^{* * *}$ & -0.98 & $-11.1^{* \star *}$ & -0.49 & $-3.89^{* \star *}$ & -0.78 & $-6.01^{* * *}$ \\
\hline HIKING & -0.13 & $-2.33^{* *}$ & - & - & -0.26 & $-3.27^{* * *}$ & - & - \\
\hline CAMPING & -0.16 & $-2.13^{\star *}$ & - & - & -0.05 & -0.47 & - & - \\
\hline DOG & 0.18 & $3.40^{* * *}$ & - & - & 0.10 & 1.40 & - & - \\
\hline HORSE & 0.23 & $2.60^{\star \star \star}$ & - & - & 0.25 & $2.18^{\star *}$ & - & - \\
\hline HUNTING & 0.10 & 1.24 & - & - & 0.29 & $2.62^{* *}$ & - & - \\
\hline BIRDWATCH & - & - & -0.12 & $-2.21^{* *}$ & - & - & -0.24 & $-3.16^{\star * *}$ \\
\hline CANOE & - & - & -0.11 & -1.45 & - & - & -0.04 & -0.34 \\
\hline MOTORBOAT & - & - & 0.11 & 1.762 & - & - & 0.14 & 1.56 \\
\hline FISHING & - & - & 0.15 & $2.66^{\star \star \star}$ & - & - & 0.27 & $3.21^{* * *}$ \\
\hline SWIMMING & & - & 0.19 & $2.98^{\star \star \star}$ & - & - & 0.10 & 1.11 \\
\hline NGO & -0.15 & $-2.00^{\star *}$ & -0.22 & $-2.99^{\star * \star}$ & -0.14 & -1.32 & -0.29 & $-2.47^{\star *}$ \\
\hline \multirow[t]{4}{*}{ Intercepts } & -1.89 & & -1.76 & & -0.54 & $-2.14^{\star *}$ & -0.09 & -0.33 \\
\hline & -0.65 & & -0.99 & & & & & \\
\hline & 0.21 & & -0.23 & & & & & \\
\hline & 0.82 & & 0.63 & & & & & \\
\hline $\mathrm{N}$ & \multicolumn{2}{|c|}{1823} & \multicolumn{2}{|c|}{1824} & \multicolumn{2}{|c|}{1782} & \multicolumn{2}{|c|}{1792} \\
\hline Pseudo $\mathrm{R}^{2}$ & \multicolumn{2}{|c|}{0.0605} & \multicolumn{2}{|c|}{0.0860} & \multicolumn{2}{|c|}{0.1525} & \multicolumn{2}{|c|}{0.1544} \\
\hline Log likelihood & \multicolumn{2}{|c|}{-2523.4} & \multicolumn{2}{|c|}{-2633.0} & \multicolumn{2}{|c|}{-908.1} & \multicolumn{2}{|c|}{-868.4} \\
\hline
\end{tabular}

Note: Three, two and one stars indicate significance at $1 \%, 5 \%$ and $10 \%$ respectively.

Note: In the probit model, 1 corresponds to "Most preferred level > Least preferred level", while 0 denotes "Most preferred level < Least preferred level". 
Table A2.2 Regression of framing effects in Denmark

\begin{tabular}{|c|c|c|c|c|c|c|c|c|}
\hline \multirow[b]{3}{*}{ Variable } & \multicolumn{4}{|c|}{ Ordered Probit for most preferred levels } & \multicolumn{4}{|c|}{$\begin{array}{l}\text { Probit model for relative order of } \\
\text { most and least preferred levels }\end{array}$} \\
\hline & \multicolumn{2}{|c|}{ Land index } & \multicolumn{2}{|c|}{ Water index } & \multicolumn{2}{|c|}{ Land index } & \multicolumn{2}{|c|}{ Water index } \\
\hline & Coefficient & $\mathrm{t}$-value & Coefficient & t-value & Coefficient & t-value & Coefficient & $\mathrm{t}$-value \\
\hline PUBLIC & 0.11 & $1.75^{\star}$ & 0.09 & 1.55 & -0.04 & -0.44 & 0.03 & 0.33 \\
\hline COMMITTED & -0.14 & $-2.30^{\star *}$ & -0.26 & $-4.27^{\star * *}$ & -0.18 & $-2.03^{* *}$ & -0.15 & -1.44 \\
\hline FEMALE & 0.06 & 1.21 & 0.06 & 1.14 & 0.03 & 0.45 & -0.07 & -0.83 \\
\hline AGE & -0.003 & -1.38 & -0.01 & $-2.76^{\star * *}$ & -0.001 & -0.28 & -0.001 & -0.19 \\
\hline EDUCATION & -0.02 & -1.25 & -0.01 & -0.53 & -0.08 & $-3.46^{* * *}$ & -0.09 & $-3.40^{* * *}$ \\
\hline INCOME (log) & -0.02 & -1.08 & -0.001 & -0.04 & -0.02 & -0.74 & 0.02 & 0.55 \\
\hline KIDS & -0.06 & -0.90 & 0.11 & $1.85^{\star}$ & 0.002 & 0.02 & 0.16 & 1.57 \\
\hline SINGLE & -0.14 & $-2.00^{* *}$ & 0.01 & 0.20 & -0.003 & -0.03 & 0.05 & 0.46 \\
\hline SELFEMP & -0.28 & $-2.58^{* * *}$ & -0.25 & $-2.35^{\star *}$ & -0.08 & -0.48 & -0.04 & -0.23 \\
\hline VISITTH & 0.16 & $2.68^{* * *}$ & -0.04 & -0.75 & -0.08 & -0.99 & -0.08 & -0.83 \\
\hline BIRDWATCH & -0.08 & -1.48 & -0.12 & $-2.02^{* *}$ & -0.16 & $-1.93^{*}$ & -0.31 & $-3.32^{* * *}$ \\
\hline BERRIES & -0.14 & $-2.38^{\star *}$ & -0.18 & $-3.02^{* \star *}$ & -0.18 & $-2.05^{\star *}$ & -0.22 & $-2.00^{\star *}$ \\
\hline HIKEOFTEN & -0.16 & $-2.96^{\star * *}$ & -0.08 & -1.46 & -0.09 & -1.12 & -0.05 & -0.51 \\
\hline BIKE & 0.29 & $5.10^{* * *}$ & - & - & 0.09 & 1.12 & - & - \\
\hline DOG & 0.25 & $4.21^{* * *}$ & - & - & 0.31 & $3.77^{\star * \star}$ & - & - \\
\hline HORSE & 0.33 & $2.54^{\star \star}$ & - & - & -0.0003 & 0.002 & - & - \\
\hline HUNTER & -0.31 & $-2.70^{* * *}$ & - & - & -0.03 & -0.15 & - & - \\
\hline CANOE & - & - & 0.23 & $3.64^{* * *}$ & - & - & 0.22 & $2.15^{\star \star}$ \\
\hline FISHING & - & - & 0.09 & 1.30 & - & - & 0.10 & 0.88 \\
\hline SWIMMING & - & - & 0.10 & $1.79^{*}$ & - & - & -0.13 & -1.34 \\
\hline NGO & -0.04 & 0.06 & -0.15 & $-2.44^{\star *}$ & -0.15 & -1.61 & -0.44 & $-3.48^{\star \star *}$ \\
\hline \multirow[t]{4}{*}{ Intercepts } & -1.85 & & -1.87 & & -0.44 & $-2.03^{\star *}$ & -0.72 & $-2.80^{* * *}$ \\
\hline & 0.83 & & 1.07 & & & & & \\
\hline & 2.42 & & 2.54 & & & & & \\
\hline & 3.61 & & 3.36 & & & & & \\
\hline $\mathrm{N}$ & \multicolumn{2}{|c|}{1961} & \multicolumn{2}{|c|}{1964} & \multicolumn{2}{|c|}{1907} & \multicolumn{2}{|c|}{1923} \\
\hline Pseudo $R^{2}$ & \multicolumn{2}{|c|}{0.025} & \multicolumn{2}{|c|}{0.029} & \multicolumn{2}{|c|}{0.044} & \multicolumn{2}{|c|}{0.072} \\
\hline Log likelihood & \multicolumn{2}{|c|}{-2276.7} & \multicolumn{2}{|c|}{-2460.8} & \multicolumn{2}{|c|}{-745.6} & \multicolumn{2}{|c|}{-550.2} \\
\hline
\end{tabular}

